\title{
Experimental Study of Performance \& Emission Analysis of Rice bran oil as an Alternative fuel for an I.C.Engine
}

\author{
Umesh $\mathrm{T}^{1}$, Manjunath $\mathrm{H} \mathrm{N}^{2}$, Rukmangadha $\mathrm{P}^{3}$, Dr.Madhu $\mathrm{D}^{4}$ \\ ${ }_{1,2}$ (Department of Mechanical Engineering, Nitte Meenakshi Institute of Technology, Bangalore-560064, India) \\ ${ }^{3}$ (Department of Mechanical Engineering, S.J.C Institute of Technology, Chickballapur-562101, India) \\ ${ }^{4}$ (Department of Mechanical Engineering, Govt. Engineering College, K.R.Pete, India)
}

\begin{abstract}
The two alarming situations in front of the engineers worldwide is to reduce the load on the conventional fuels and to reduce the ever increasing environmental pollution. This study is aimed to investigate experimentally the performance and exhaust emission characteristics of a diesel engine when fuelled with diesel and methyl esters of rice bran oil in various proportions. Experiments were conducted on a 4-cylinder directinjection diesel engine. The engine speed was maintained at $1500 \mathrm{rpm}$. The result indicates that the performance characteristics of B-20 blend was superior to all other blends of fuels. According to emission test, emission levels of $\mathrm{HC}, \mathrm{NOx}, \& \mathrm{CO}_{2}$ decreased with blending percentage increased. These results indicate that the rice bran methyl ester can be used in C.I. engine without any major modifications.
\end{abstract}

Keywords: alternative fuels, engine performance, exhaust emissions, rice bran oil

\section{Introduction}

Worldwide energy demands are increasing day-by-day. Major part of it is contributed by fossil fuels.

Fossil fuels have played a dominant role in the rapid industrialization of the world and thereby increased and improved quality of life. Unhindered use of these fuels has also given rise to environmental issues. The burning of petroleum fuel is associated with emission like $\mathrm{CO}_{2}, \mathrm{CO}$, NOx and particulate matter, which are currently the dominated global source of emission. Hence, the petroleum fuel is responsible for the pollutions and global warming. These in turn have resulted in the additional expenses by way of additional spending on the protection of the citizens of the country from the ecological ill-effects, replacement of equipment, infrastructure for both the old and the new technology, etc. Therefore, all over the world, scientists and engineers have been in the constant search for alternative sources to meet the energy needs and to develop the eco-friendly fuel.

Biodiesel is one of the most promising alternative fuels for diesel engines. Biodiesel became more and more attractive in recent years. Biodiesel is defined as a fuel comprising of mono alkyl esters of long chain fatty acids derived from vegetable oil or animal fat. Biodiesel contains no petroleum but it can blend at any level with petroleum diesel to create a biodiesel blend. It can be used in CI engine with no major modifications. It is simple to use, bio degradable, non-toxic and essentially free of Sulphur and aromatics.

There are three types of oil which are possible sources for biodiesel production; they are Vegetable oil, Animal fat, and used cooking oil [1]-[4].

Biodiesel is generally produced by trans-esterification of vegetable oil, animal fats and waste cooking oil. Trans-esterification is the conversion of one ester into other. Trans-esterification process is generally called alcoholysis as the original ester is reacted with alcohol. Glycerol is the byproduct of the reaction. The most commonly used alcohol is methanol. The reaction is completed in the presence of catalyst. The catalyst used can be acidic or basic. Catalysts used are generally potassium hydroxide $(\mathrm{KOH})$ or sodium hydroxide $(\mathrm{NaOH})$, as base catalyst. The main purpose of trans-esterification is to reduce the viscosity. Lower viscosity solves the problem of engine choking. There are various feed stocks available for production of biodiesel [5]-[6]

Rice bran oil is a potential resource for production of biodiesel, because of its mineral diesel like properties, to augment the diesel use in at least the sectors like irrigation, water-ways transportation, and small diesel fuelled community power-plants etc. A major physical advantage of rice bran oil is locally availability, and less processing infrastructure, while its limitation is its high density, viscosity and suspended particulates.

Rice bran oil is extracted from the germ and inner husk generally known as bran which is a byproduct of rice processing industry. $15-20 \%$ of oil content is present in rice bran oil. India is the second largest producer of rice, next to China. Recent survey has shown India as the largest producer of rice bran oil in the world. The oill extracted has to be blended in a particular proportion with petroleum diesel. The blended fuel should possess an improved or an equivalent performance characteristic as that of diesel. Various researchers have recommended B20 (20\% biodiesel, $80 \%$ diesel) as the most appropriate blend to be used as fuel in diesel engine without any modification to the engine. 


\subsection{Experimental set-up}

\section{Materials And Methodology}

In the present investigation Kirloskar single cylinder, four stroke, water cooled diesel engine is used for comparing the performance and emission characteristics of diesel, and biodiesel blends. The photograph of the experimental set-up is shown in Figs 1. The specification of the tested engine is presented in Table 1.

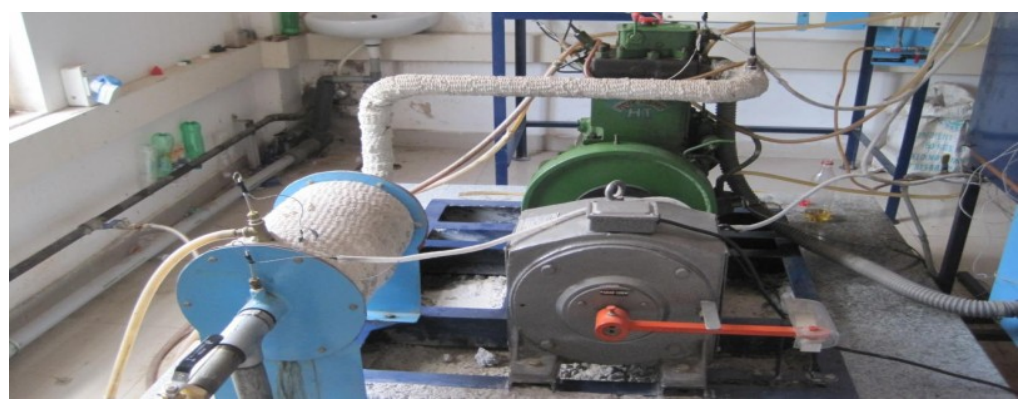

Fig; 1 Photograph of the experimental set-up

Table1; Specification of the engine used to carry out the experiment

\begin{tabular}{|c|c|}
\hline Make & Kirloskar \\
\hline Capacity & $3.7 \mathrm{KW}$ \\
\hline Compression Ratio & 16.5 .1 \\
\hline Bore & $80 \mathrm{~mm}$ \\
\hline Stroke & $110 \mathrm{~mm}$ \\
\hline Cylinder Capacity & $553 \mathrm{CC}$ \\
\hline
\end{tabular}

\subsection{Materials}

In the present experiments are used the materials such as, refined Rice bran oil, Methanol (alcohol) and Potassium hydroxide $(\mathrm{KOH})$ are used as a base catalyst. Refined rice bran oil popularly known as rice bran health was purchased from local general provision store. The transesterification carried out at bio fuel laboratory. Methanol and Potassium hydroxide were used to carry out the transesterification in water bath shaker.

\subsection{Transesterification Process}

Refined rice bran oil was used for the extraction of biodiesel with a single stage base catalyzed transesterification method. The following procedure was used to prepare the bio diesel.

Known quantity of rice bran oil was taken in a conical flask then the oil in the flask was heated up to a temperature of $110^{\circ} \mathrm{C}$. A mixture of known quantity of Potassium hydroxide $(\mathrm{KOH})$ as base catalyst and methanol was then mixed with the oil. The preheated oil was further subjected to an alkali catalyzed transesterification with methanol as alcohol and $\mathrm{KOH}$ as catalyst with constant stirring for 1 hour in water bath shaker at $60^{\circ} \mathrm{C}$. The un-reacted catalyst along with methanol and the residual glycerol were removed by the water washing method (3-5 times) using hot distilled water until the water became clear. After washing, the crude rice bran biodiesel was heated on a oil hot plate for 15-20 minutes to remove water and methanol content present in it. After washing and drying, various properties were investigated. Table; 2 shows the properties of rice bran biodiesel

Table 2: Properties of diesel and biodiesel and their blends

\begin{tabular}{|c|c|c|c|c|c|}
\hline Fuel & $\begin{array}{l}\text { Specific } \\
\text { gravity }\end{array}$ & $\begin{array}{l}\text { Kinematic } \\
\text { viscosity }\left(\mathrm{m}^{2} / \mathrm{s}\right)\end{array}$ & $\begin{array}{c}\text { Flash } \\
\text { Point } \\
\left({ }^{\circ} \mathrm{C}\right)\end{array}$ & $\begin{array}{c}\text { Fire } \\
\text { Point } \\
\left({ }^{\circ} \mathrm{C}\right)\end{array}$ & Diesel \\
\hline Diesel & 0.82 & $2.50 \times 10^{-6}$ & 53 & 56 & 42933 \\
\hline B-10 & 0.822 & $2.76 \times 10^{-6}$ & 54 & 57 & 42693 \\
\hline B-20 & 0.839 & $3.09 \times 10^{-6}$ & 55 & 58 & 42453 \\
\hline B-30 & 0.842 & $3.16 \times 10^{-6}$ & 57 & 60 & 42213 \\
\hline B-40 & 0.863 & $3.88 \times 10^{-6}$ & 59 & 62 & 41973 \\
\hline B-50 & 0.885 & $4.38 \times 10^{-6}$ & 63 & 66 & 41734 \\
\hline B100 & 0.885 & $5.9 \times 10^{-6}$ & 167 & 171 & 40535 \\
\hline
\end{tabular}




\section{Results and Discussions}

The performance and emission characteristics for the various load conditions of different fuels were analyzed and the results are presented in the following sections.

\subsection{Performance Results}

\subsubsection{Brake thermal efficiency}

The variation of brake thermal efficiency with brake power for diesel, biodiesel and different blends is shown in the Fig; 2

The brake thermal efficiency increased as the load on the engine increased. The brake thermal efficiency of the B20 Blended fuel is highest than the all other fuels. The brake thermal efficiency decreased as the proportion of rice bran oil increased. This can be explained by the fact that as the viscosity of the blend increased, the atomization of fuel is not as good as pure diesel.

\subsubsection{Brake specific fuel consumption}

The brake specific fuel consumption reduced with increase in brake power for all fuel modes. From the Fig; 3 it is evident that the brake specific fuel consumption of the B20 blend is much less when compared to diesel and other blends. As the proportion of rice bran oil increased in the blends, specific fuel consumption increased as shown in Fig: 4. higher proportions of rice bran oil in the blends increased the viscosity which in turn increased the specific fuel consumption due to poor atomization of the fuel.

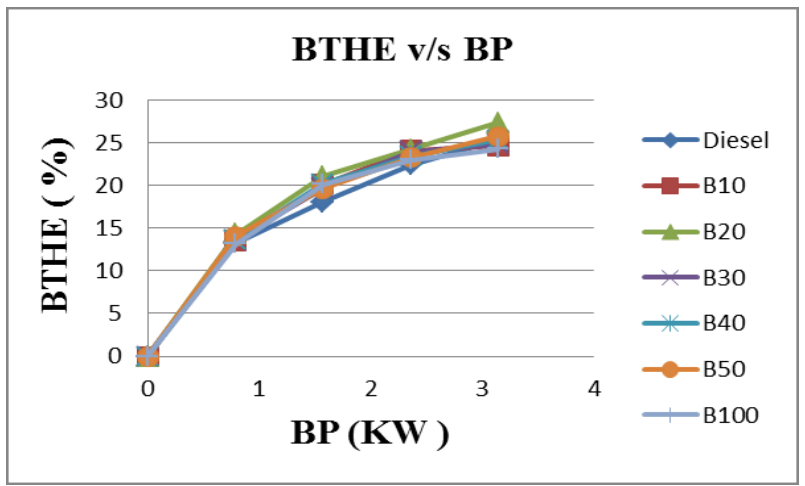

Fig 2: Brake thermal efficiency v/s Brake power

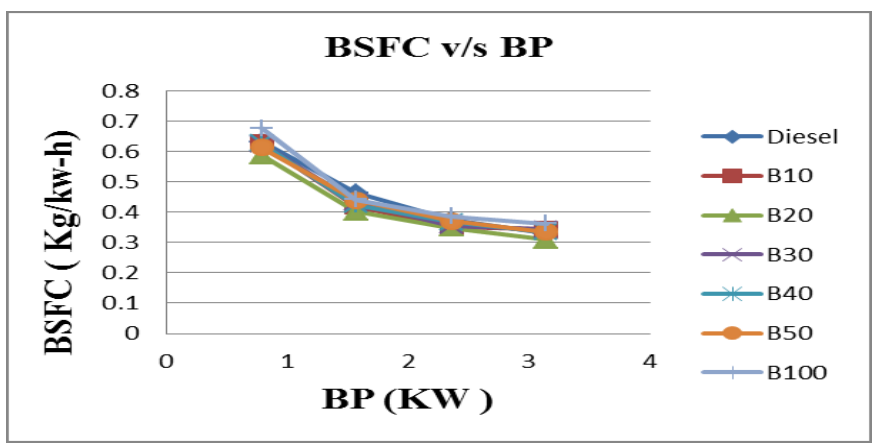

Fig 3: Brake specific fuel consumption v/s Brake power

\subsection{Emission Results}

\subsubsection{Carbon dioxide emission}

The $\mathrm{CO}_{2}$ emissions increased with increase in brake power for all the fuel samples due to the higher fuel entry as the loads increases Fig; 4. The $\mathrm{CO}_{2}$ emission for diesel and $\mathrm{B} 10$ were higher at the higher brake power than the other blends. The lowest $\mathrm{CO}_{2}$ emissions were observed for $\mathrm{B} 40$, the reason could be the better combustion of biodiesel.

\subsubsection{Hydro carbon emission}

The hydrocarbon emission increased with the increase in brake power Fig; 5. At higher load the effects of viscosity have increased hydrocarbon emission for the blends. At the higher brake power, the hydrocarbon emission for the B50 is less, compared to the conventional diesel and other blends. 


\subsubsection{Oxides of nitrogen emission}

The $\mathrm{NO}_{\mathrm{X}}$ emission for diesel and all the blends followed increasing trends with respect to the brake power. Fig; 6 For Diesel \& B10 showing the higher $\mathrm{NO}_{\mathrm{X}}$ emission and $\mathrm{NO}_{\mathrm{X}}$ emissions decreased with the increase of addition of rice bran oil in the blends.

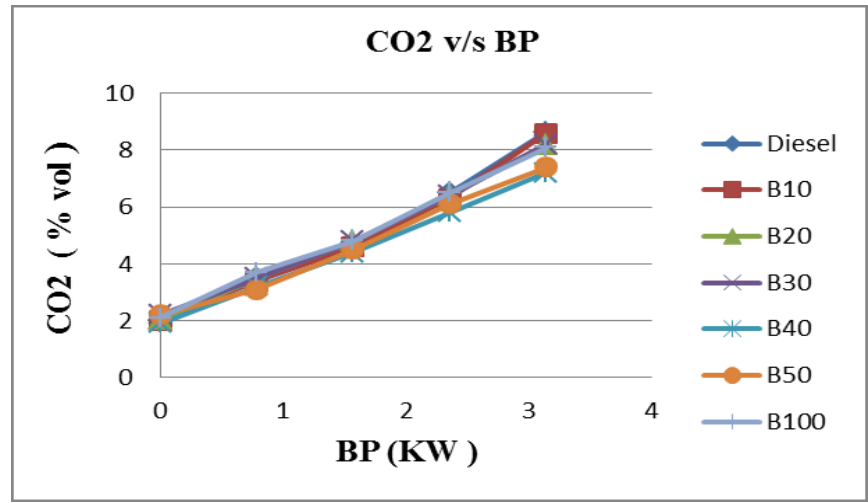

Fig; 4 Variation of emission of $\mathrm{CO}_{2}$ vs $\mathrm{BP}$

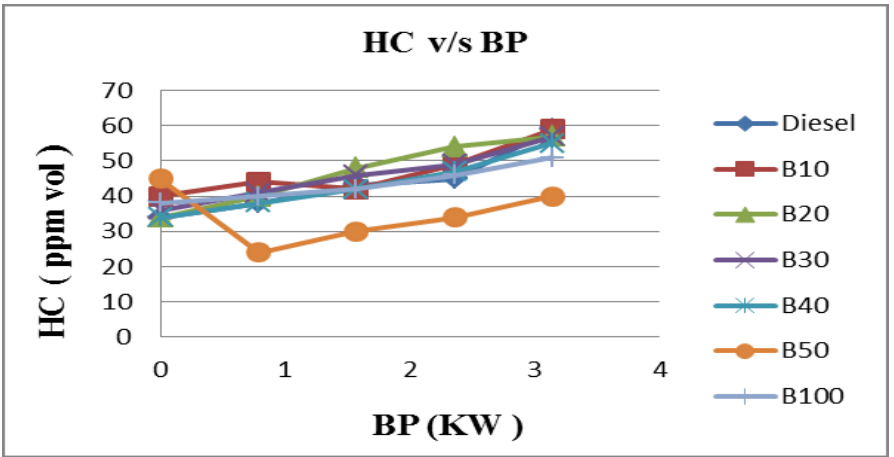

Fig; 5 Variation of emission of $\mathrm{HC}$ vs BP

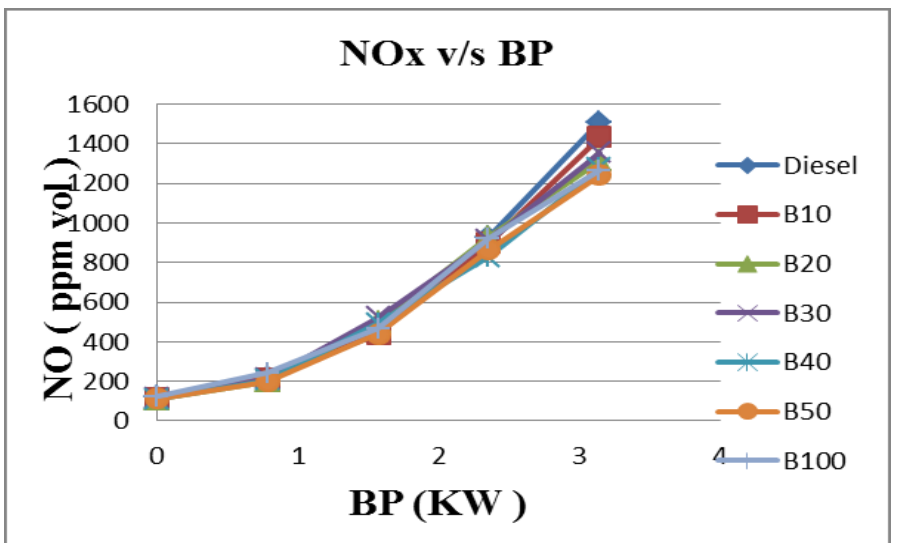

Fig; 6 Variation of emission of NOx vs BP

\section{Conclusion}

The performance and emission characteristics of diesel, rice bran oil and the blends obtained from the experiment on a single cylinder, four strokes, direct injection diesel engine can be concluded as follows:

The method employed to prepare the biodiesel is the transesterification process which reduces the viscosity of the fuel by a certain amount, thereby making it usable in Internal Combustion Engines. For B20 fuel, Brake thermal efficiency was found to have maximum value and specific fuel consumption was found to be lowest. Higher oxygen content in biodiesel fuel than that of diesel fuel caused lower smoke emissions.

For B40 and B50 fuels showed better hydro carbon and carbon dioxide emissions than diesel fuel. NOx emissions reduced for all the blends at different loads compared to diesel emissions .Addition of a bio fuel in a limited proportion reduce air pollution to large extent. 
From the overall study of performance as well as emission characteristics of diesel, biodiesel and its blends, we can conclude that methyl esters of rice bran oil can be used as alternative to the fossil diesel

\section{References}

[1] Fukuda Hideki, Kondo Akihiko, Noda Hideo, 2001 "Biodiesel fuel production by transesterification of oils," J. Bioscience and Bioengineering, vol. 92, pp. 405-416.

[2] Ma Fangrui, Hanna Milford A., "Biodiesel production: a review," Bioresource Technology," vol. 70, pp. 1-15.

[3] Gerpen Jon V., "Biodiesel processing and production,” 2005 Fuel Processing Technology, vol. 86, pp. 1097- 1107.

[4] Leung Dennis Y.C, Wu Xuan, Leung M.K.H, “A review of biodiesel production using catalyzed transesterification,”2010 Applied Energy, vol. 87, pp. 1083-1095.

[5] Balat Mustafa, "Potential alternatives to edible oils for biodiesel production- A review of current work," Energy Conversion and Management, 2011 vol. 52, pp. 1479-1492.

[6] Ju Yi-Hsu, Vali Shaik R., "Rice bran oil as a potential resource for biodiesel: A review," 2005 J. Scientific \& Industrial Research, vol. 64 , pp. 866-882. 